Article

\title{
Efficiency Improvement Strategy for Multiple Operating Points in Doubly Fed Magnetic Geared Motor
}

\author{
Homin Shin 1 and Junghwan Chang *(i) \\ Mechatronics System Research Lab., Department of Electrical Engineering, Dong-A University, Saha-gu, \\ Busan 49315, Korea; sinhomin@nate.com \\ * Correspondence: cjhwan@dau.ac.kr; Tel.: +82-051-200-7735
}

Received: 10 March 2020; Accepted: 31 March 2020; Published: 3 April 2020

\begin{abstract}
The doubly fed magnetic geared motor, which has dual AC windings, can be operated with different frequencies in the inner and outer windings. However, the inner and outer windings have different numbers of pole pairs to meet the pole combination derived by the magnetic gearing effect, and hence undesirable space harmonic components of the magnetic flux are produced at the air gaps. These space harmonics affect the iron losses at each core, and the resultant iron loss and efficiency are varied by the frequencies of the inner and outer windings. Thus, in this paper, first, the effect of the space harmonic components of the air gap magnetic flux density in the inner stator, outer stator, and the modulating pieces is separately investigated. In addition, the iron loss characteristics of each ferromagnetic material are presented according to the frequency combinations in the inner and outer windings. Secondly, the iron loss maps and the efficiency maps according to the frequency conditions of the inner and outer windings are drawn, and the causes of the characteristic differences in each map are analyzed. Thirdly, the frequency control sequence and the roles of the inner and outer windings as the armature and field parts are changed, and the analysis of the iron loss map and efficiency map is repeated. Finally, the results in the inner-armature case and the outer-armature case are compared with each other, and the possibility of improving the overall operating efficiency over the multiple operating points by using the individual frequency control and frequency combination selection is proved.
\end{abstract}

Keywords: coaxial magnetic gear; doubly fed magnetic geared motor; electric vehicles (EVs); electric continuously variable transmission (E-CVT); magnetic geared machine

\section{Introduction}

The magnetic geared motor, which is devised from the magnetic gear, has been widely reported in direct-drive system and low-speed, high-torque applications. As shown in Figure 1a, unlike the general synchronous machine, the magnetic geared motor has modulating pieces which modulate the winding magnetic flux and the permanent magnets (PMs) magnetic flux, respectively. A modulating part consists of a pole piece with ferromagnetic material to modulate the magnetic flux and a supporting body with nonmagnetic material to hold each piece which can play a role as a fixed part or output rotor. In a case in which a modulating part is used as the rotor, the gear ratio is larger than that of the PM rotor case. The winding magnetic flux is changed into the magnetic field with a high number of poles by the magnetic gearing effect, and it is synchronized with the PM magnetic flux [1]. Thus, the speed of the PM rotor is reduced by the ratio of the pole numbers of the winding and the PMs, and the output torque is inversely increased by the same ratio. Due to these characteristics, many studies on the magnetic geared motor have focused on low-speed, high-torque applications, and there are continued efforts to replace the power transmission of an electric vehicle (EV) consisting of the 
synchronous machine and a mechanical gear box with a magnetic geared motor [2-9]. However, the fact that the range of the field weakening operation gets narrower as the ratio of PM MMF to winding MMF increases, and the unstable price and supply with respect to rare earth materials are regarded as the shortcomings in the traction applications including the EVs.

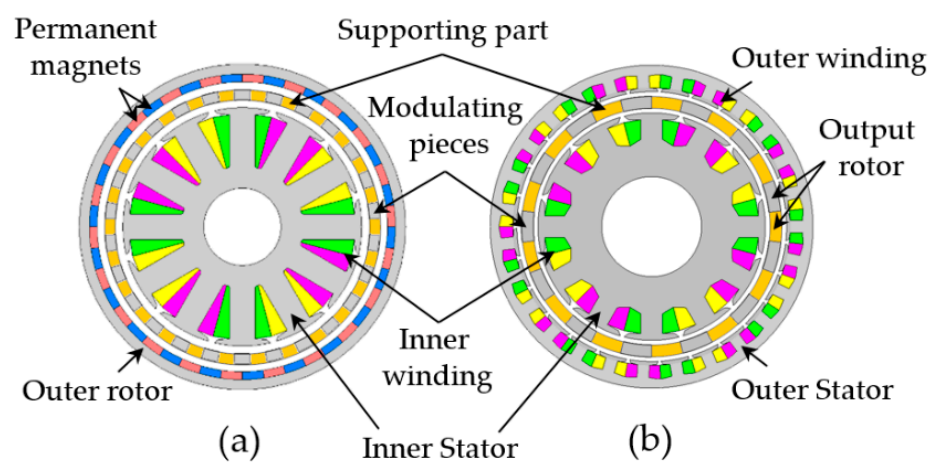

Figure 1. Topologies of the magnetic geared machine. (a) PM magnetic geared motor; (b) doubly fed magnetic geared motor (DFMGM).

Meanwhile, as shown in Figure 1b, recently, the doubly fed magnetic geared motor (DFMGM), with three-phase windings and alternating current (AC) in both inner and outer stators, has been researched [10-15]. In a DFMGM, the modulating part is used as the output rotor, and the speed of the output rotor is determined by the frequencies of the inner and outer windings. Furthermore, the number of pole pairs in each winding and the number of modulating pieces are determined by the magnetic gearing effect, and thanks to this operating principle, the base speed of the DFMGM can be increased as compared with the case of only one three-phase AC winding stator. Otherwise, if it is not necessary to increase the output speed, the base frequency is decreased because it is designed as the summation of rated frequencies of the inner and outer windings. Namely, the base frequency is divided up into two low frequencies which means that the inner and outer parts share the whole operating region. Hence, the one high power inverter, which is required to reach the base speed, can be split into two low capacity inverters. However, in the motor which is operated by the principle of magnetic field modulation, undesirable space harmonic components are produced at the air gaps, and their effect is severe when the operating frequencies of the inner and outer windings are different from each other. Especially, the unmodulated space harmonic, which does not synchronize with the working harmonic at the air gap, significantly affects the magnetic loss. Furthermore, these space harmonics have different influences on the iron losses at each stator and the modulating pieces, respectively, and the resultant iron losses at each part and the efficiency are varied by how the frequency of each winding is designed. Accordingly, it is very important to determine the frequency ranges of the inner and outer windings considering iron loss depending on the space harmonics. Thus, this paper presents the characteristics of space harmonics and iron loss according to the frequencies of the inner and outer windings and proposes a concept for efficiency improvement by using individual frequency control and frequency combination selection.

\section{Operating Principle}

The speed of an output rotor is adjusted by the frequencies of the inner and outer windings, and it is defined as in Equation (1) [11]:

$$
\omega_{\text {output_MPs }}=\frac{p_{\text {inner }}}{N_{M P s}} \omega_{\text {inner }}+\frac{p_{\text {outer }}}{N_{M P s}} \omega_{\text {outer }}
$$

where $p_{\text {inner }}$ and $p_{\text {outer }}$ are the number of pole pairs of the inner and outer windings, $N_{M P s}$ is the number of modulating pieces, $\omega_{\text {inner }}$ and $\omega_{\text {outer }}$ are the mechanical angular velocities of the fundamental 
components of the magnetic flux produced by the inner and outer windings. In the DFMGM, the operating region can be divided into two subregions according to the winding in which the frequency is changed. Figure 2 shows examples of the speed-torque curve for the DFMGM with the different rated frequencies in the inner and outer windings under the condition that the inner winding frequency is increased in the low-speed region and the outer winding frequency is adjusted in the high-speed region. In Figure $2 \mathrm{a}-\mathrm{c}$, the inner and outer rated frequencies $\left(f_{\text {inner }}\right.$ and $\left.f_{\text {outer }}\right)$ are $180 \mathrm{~Hz}$ and $360 \mathrm{~Hz}$ (Type I), $270 \mathrm{~Hz}$ and $270 \mathrm{~Hz}$ (Type II), and $360 \mathrm{~Hz}$ and $180 \mathrm{~Hz}$ (Type III), respectively. The base speeds $\left(\omega_{\text {base_I }}\right.$ and $\left.\omega_{\text {base_II }}\right)$ of each operating type are derived as follows:

$$
\begin{aligned}
& \text { Type I } 2492 \mathrm{rpm}\left(\omega_{\text {base II }_{I I}}\right)=831 \mathrm{rpm}\left(=\omega_{\text {base }_{I}}\right)+1661 \mathrm{rpm} \\
& \text { Type II } 2492 \mathrm{rpm}\left(\omega_{\text {base_II }}\right)=1246 \mathrm{rpm}\left(=\omega_{\text {base_I }}\right)+1246 \mathrm{rpm} \\
& \text { Type III } 2492 \mathrm{rpm}\left(\omega_{\text {base_II }}\right)=1661 \mathrm{rpm}\left(=\omega_{\text {base_I }}\right)+831 \mathrm{rpm}
\end{aligned}
$$

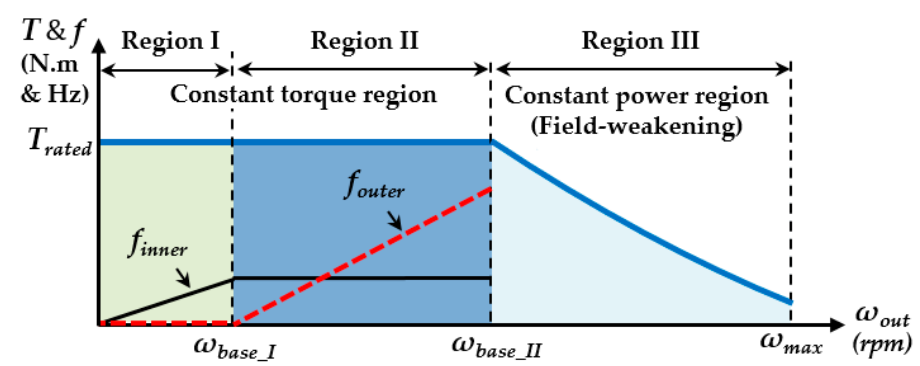

(a)

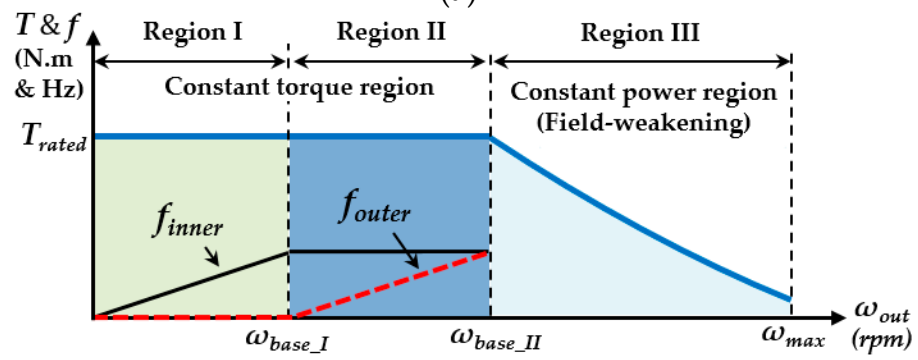

(b)

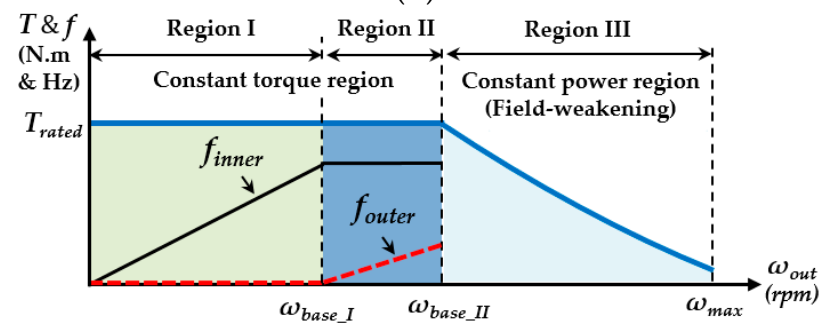

(c)

Figure 2. Division of the operating region according to the rated frequencies of the inner and outer windings. (a) Type I ( $f_{\text {inner }} 180 \mathrm{~Hz}$ and $f_{\text {outer }} 360 \mathrm{~Hz}$ ); (b) Type II $\left(f_{\text {inner }} 270 \mathrm{~Hz}\right.$ and $\left.f_{\text {outer }} 270 \mathrm{~Hz}\right) ;(\mathbf{c})$ Type III ( $f_{\text {inner }} 360 \mathrm{~Hz}$ and $\left.f_{\text {outer }} 180 \mathrm{~Hz}\right)$.

In the low-speed region, while the frequency of the outer winding is fixed at $0 \mathrm{~Hz}$ corresponding to the DC operation, the frequency of the inner winding is increased until the base speed I, $\omega_{\text {base_ } I}$. Then, the frequency of the outer winding is increased until the base speed II, $\omega_{\text {base_II }}$, while the frequency of the inner winding is fixed at its rated value. Meanwhile, to adjust the output torque, the current of inner winding, which plays a role as the armature part, is controlled, and the current of the outer winding, which plays a role as the field part, is fixed at its rated value. The design specifications are listed in Table 1. 
Table 1. Specifications of the analysis model.

\begin{tabular}{cc}
\hline Contents & Value \\
\hline Diameter $(\mathrm{mm})$ & 269 \\
Stack length $(\mathrm{mm})$ & 156 \\
Number of pole pairs of inner winding & 4 \\
Number of pole pairs of outer winding & 9 \\
Number of modulating pieces & 13 \\
Base speed (rpm) & 2492 \\
Current density of wire $\left(\mathrm{A}_{\mathrm{rms}} / \mathrm{mm}^{2}\right)$ & 10 \\
Fill factor & 0.55 \\
Phase current (inner/outer), $\left(\mathrm{A}_{\mathrm{rms}}\right)$ & $424 / 168$ \\
Number of turns per phase (inner/outer) & $16 / 36$ \\
MMF per phase (inner/outer) (AT) & $6784 / 6048$ \\
\hline
\end{tabular}

\section{Iron Loss Characteristics}

Prior to handling the iron loss characteristics, the magnetic flux density at the inner stator, outer stator and the modulating pieces are presented to clearly see the effect of space harmonic components on the magnetic flux variation at each part." All results are calculated in the two-dimensional (2D) domain of the commercial software, Altair Flux 2D based on finite element analysis (FEA). The number of nodes in the 2D study domain is about 268,000 , and it has a relatively large value considering dual airgaps and modulating part with fine mesh.

\subsection{Characteristics of the Magnetic Flux}

Figure 3 shows the calculation points of the radial magnetic flux density at the inner stator, outer stator, and the modulating pieces, and Figure 4 shows the time variation of the radial magnetic flux density and its time harmonic spectra at the inner stator, when the inner and outer windings operate at $180 \mathrm{~Hz}$ and $360 \mathrm{~Hz}$ (Type I), respectively. Although the time variation of the radial magnetic flux density at the inner stator has some time harmonic components, the fundamental component corresponding to the frequency of the inner winding $(180 \mathrm{~Hz})$ is dominant. However, as shown in Figure 5, there are two large time harmonic components of the radial magnetic flux density at the outer stator. The second harmonic which corresponds to the frequency of the outer winding $(360 \mathrm{~Hz})$, and the fundamental component which corresponds to the $180 \mathrm{~Hz}$, are produced by the fundamental component of the magnetic flux of the inner winding. Furthermore, the amplitude of the fundamental component is almost half of the second harmonic $(360 \mathrm{~Hz})$. Namely, the magnetic flux of the inner winding, which has a small number of pole pairs, passes through the outer stator, and it affects the flux density variation and resultant iron loss at the outer stator [16]. Meanwhile, the time variation of the radial magnetic flux density and its time harmonic spectra at the modulating piece are presented, as shown in Figure 6 . The time variation which corresponds to $13.85 \mathrm{~Hz}$, and this frequency can be derived from the relative angular velocity difference between the modulating pieces and the fundamental component of the inner or outer magnetic flux, as in Equations (5) and (6), respectively:

$$
\begin{aligned}
& f_{\text {by_inner }}(\mathrm{Hz})=\left[f_{\text {inner }} / p_{\text {inner }}-\left(f_{\text {inner }}+f_{\text {outer }}\right) / N_{M P_{s}}\right] \times p_{\text {inner }} \\
& f_{\text {by_outer }}(H z)=\left[f_{\text {outer }} / p_{\text {outer }}-\left(f_{\text {inner }}+f_{\text {outer }}\right) / N_{M P_{s}}\right] \times p_{\text {outer }}
\end{aligned}
$$

By substituting $180 \mathrm{HZ}$ for $f_{\text {inner, }}$, and $360 \mathrm{HZ}$ for $f_{\text {outer }}$, into Equations (5) and (6), the frequencies of the time variation of the radial magnetic flux density caused by the inner and outer magnetic flux are obtained as in Equations (7) and (8), respectively:

$$
\begin{aligned}
& +13.85 \mathrm{~Hz}=[180 \mathrm{~Hz} / 4-(180 \mathrm{~Hz}+360 \mathrm{~Hz}) / 13] \times 4 \\
& -13.85 \mathrm{~Hz}=[360 \mathrm{~Hz} / 9-(180 \mathrm{~Hz}+360 \mathrm{~Hz}) / 13] \times 9
\end{aligned}
$$


The time variation frequencies by the inner and outer magnetic flux are the same for each other. However, the positive sign, (+) of Equation (7) means that the fundamental component of the inner magnetic flux is faster than the modulating pieces, and the negative sign of Equation (8) means the modulating pieces are faster than the fundamental component of the outer magnetic flux.

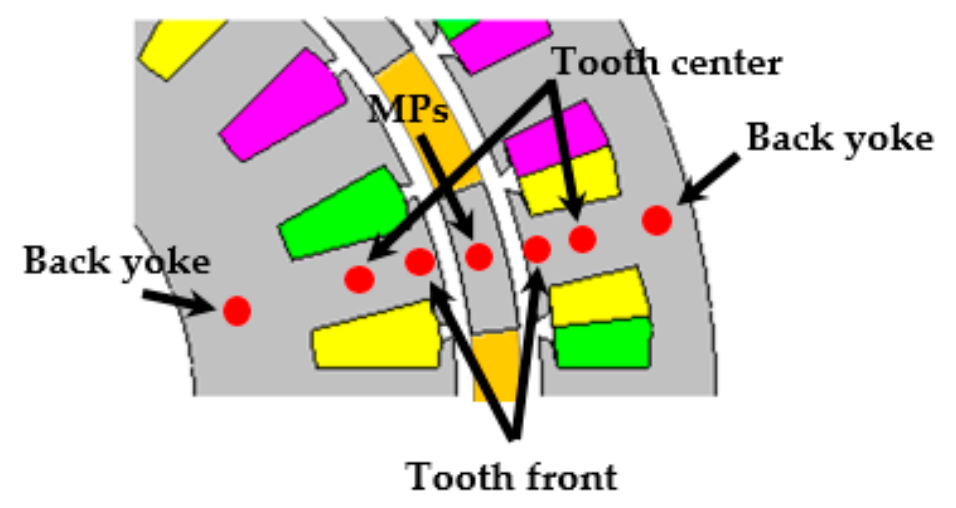

Figure 3. Calculation points of the radial flux densities in the inner stator, outer stator, and the modulating pieces.

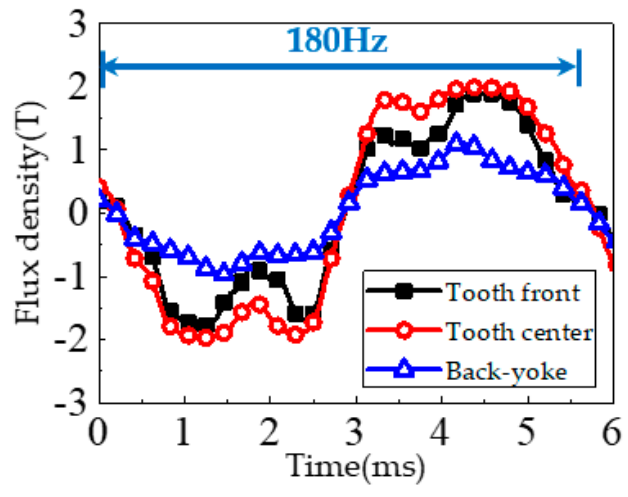

(a)

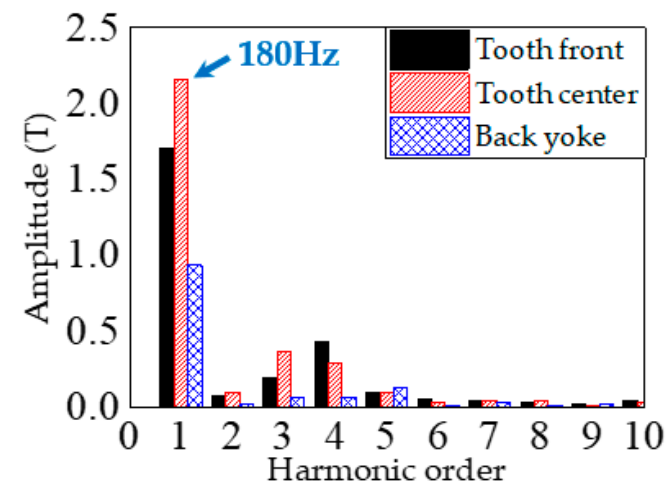

(b)

Figure 4. Variation of the radial magnetic flux densities with time at the front of tooth, center of tooth, and back yoke in the inner stator. (a) Waveform and (b) Time harmonic spectra.

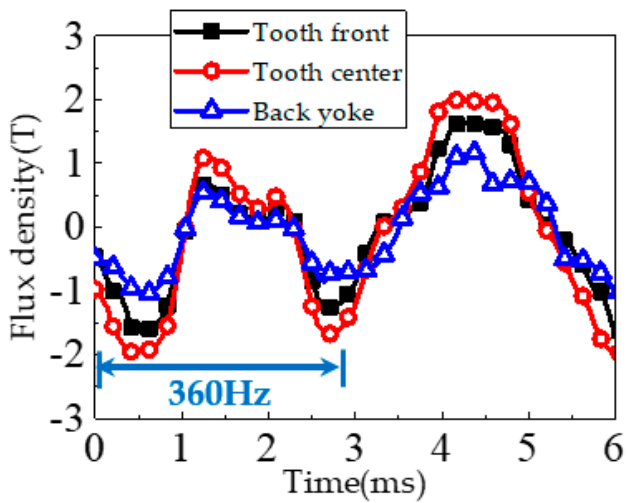

(a)

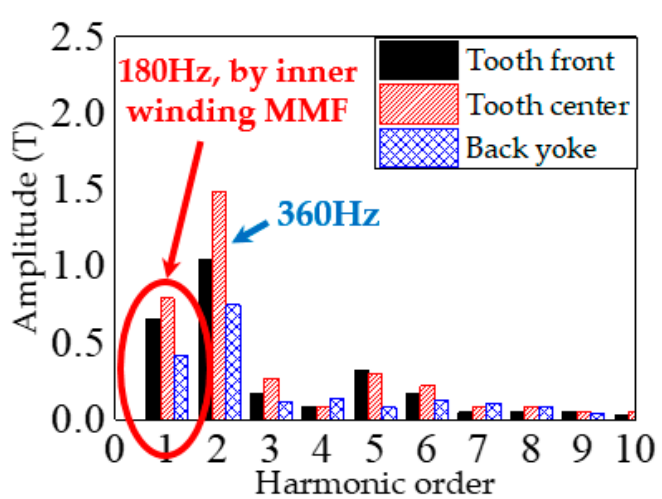

(b)

Figure 5. Variation of the radial magnetic flux densities with time at the front of tooth, center of tooth, and back yoke in the outer stator. (a) Waveform and (b) Time harmonic spectra. 


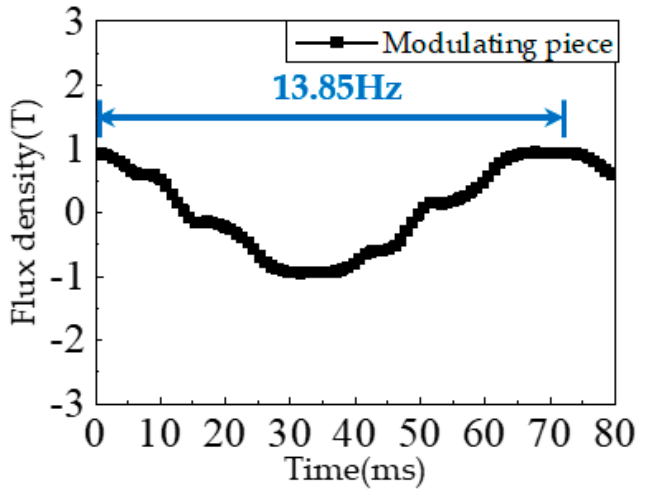

(a)

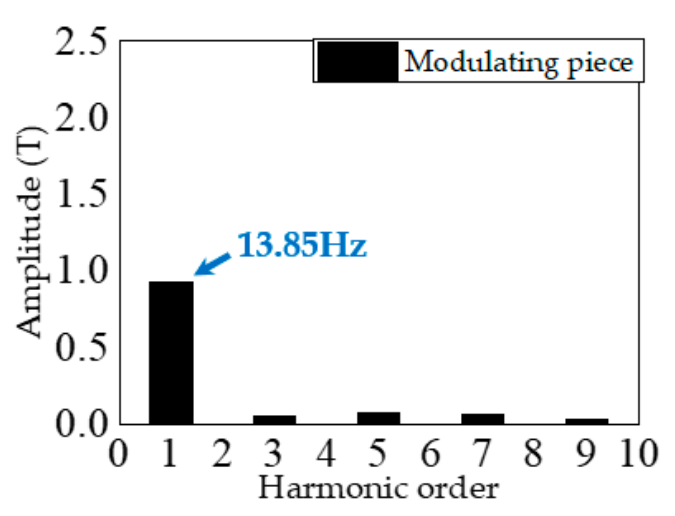

(b)

Figure 6. Variation of the radial magnetic flux densities with time at the center of modulating piece.

(a) Waveform and (b) Time harmonic spectra.

\subsection{Iron Loss According to the Frequencies of the Inner and Outer Windings}

The iron loss at each node in the 2D domain is calculated using the theory of Bertotti, and it is expressed as in (9) [17]:

$$
P_{\text {node }}=\left\{k_{h} B_{m}^{2} f+\frac{1}{T} \int_{0}^{T}\left[\sigma \frac{d^{2}}{12}\left(\frac{d B}{d t}(t)\right)^{2}+k_{e}\left(\frac{d B}{d t}(t)\right)^{3 / 2}\right] d t\right\} k_{f}
$$

where $k_{h}$ and $k_{e}$ are the coefficient of losses by hysteresis and excess, $\sigma$ is the electric conductivity and $d$ is the thickness of the lamination, $f$ and $B_{m}$ are the electric frequency and the peak value of the magnetic flux density, $k_{f}$ and $T$ are the staking factor and the time period of the magnetic flux density variation, respectively. The iron loss at the individual part in the inner stator, outer stator, and modulating pieces is given by integrating the iron loss at each node over each region. However, it should be noted that the minor loop is not considered in the hysteresis loss calculation of Equation (9). Although the calculation methods that consider the minor loop or the time harmonic of the magnetic field are handled in the application which needs the exact calculation of the iron loss, it is too time consuming when the iron losses in all operating points are calculated $[18,19]$. Thus, the fundamental component of the time variation of the magnetic field is only considered in the hysteresis loss calculation by Equation (9), and the different frequencies derived in Figures 4-6 are used in the calculations of each part, respectively.

Table 2 shows the iron loss results at the inner stator, outer stator, and the modulating pieces according to the frequencies of the inner and outer windings, when the DFMGM operates at the base speed II with the full load condition. In Table 2, whereas the iron loss at the inner stator is almost proportional to the frequency of the inner winding, the iron loss at the outer stator is not proportional to the frequency of the outer winding. In other words, the outer iron loss $(602.9 \mathrm{~W})$ in the Type III with the $180 \mathrm{~Hz}$ at the outer winding has a similar value to that $(619.0 \mathrm{~W})$ in the Type II with the $270 \mathrm{~Hz}$ at the outer winding. This is because the iron loss at the outer stator by the fundamental component of the inner magnetic flux is largely increased as the frequency of the inner winding is increasing. Furthermore, the inner iron loss $(983.4 \mathrm{~W})$ in Type III with $360 \mathrm{~Hz}$ at the inner winding are larger than the outer iron loss $(701.3 \mathrm{~W})$ in Type I with $360 \mathrm{~Hz}$ at the outer winding. Namely, under the same operating frequency, although the outer stator suffers the flux density variation by the fundamental component of inner magnetic flux, the inner stator has a greater iron loss than that of the outer stator. Hence, in the total iron loss of the ferromagnetic materials, the Type III, which has relatively high frequency at the inner winding, has the greatest iron loss.

To clearly understand these tendencies, the iron loss maps over the constant torque region of Types I, II, and III are compared. It should be noted that, as mentioned above, the amplitude of the inner winding current is adjusted with respect to the torque regulation and the frequency control 
sequence corresponds with that in Figure 2. As shown in Figure 7c, in Type III with the high frequency at the inner winding, the iron loss is increasing as it goes to the high-torque region. This tendency is natural because the inner winding current, which acts as the armature part, is large in the high-torque region. Furthermore, as shown in Figure 7d, the iron loss map for the difference between the Type III and Type I implies that the iron losses of the Type III in the high-speed and high-torque region are greater than those of the Type I and it is reversed in the high-speed and low-torque region. Namely, it is reasonable to design the high frequency at the outer winding over the high-speed and high-torque region, and it would be better to lower the frequency at the outer winding over the high-speed and low-torque region.

Table 2. Iron loss according to the frequency conditions (@2492 rpm and $210 \mathrm{Nm}$ ).

\begin{tabular}{cccccc}
\hline \multicolumn{2}{c}{ Iron Loss } & Inner & Outer & MPs & Total \\
\hline \multirow{2}{*}{ Type I $\left(f_{\text {inner }}\right.$} & Hys.(W) & 233.3 & 262.0 & 2.1 & $\cdot$ \\
$180 \mathrm{~Hz}$ and & Eddy.(W) & 299.8 & 439.2 & 158.8 & $\cdot$ \\
$\left.f_{\text {outer }} 360 \mathrm{~Hz}\right)$ & Excess(W) & 0.037 & 0.084 & 0.040 & $\cdot$ \\
& Total $(\mathrm{W})$ & 533.2 & 701.3 & 161.0 & 1395.5 \\
\hline \multirow{2}{*}{ Type II $\left(f_{\text {inner }}\right.$} & Hys.(W) & 275.5 & 236.2 & 24.0 & $\cdot$ \\
$270 \mathrm{~Hz}$ and & Eddy.(W) & 452.4 & 382.7 & 171.8 &. \\
$f_{\text {outer } 270 \mathrm{~Hz})}$ & Excess(W) & 0.097 & 0.084 & 0.041 &. \\
& Total $(\mathrm{W})$ & 727.9 & 619.0 & 195.8 & 1542.7 \\
\hline \multirow{2}{*}{ Type III $\left(f_{\text {inner }}\right.$} & Hys.(W) & 354.6 & 227.7 & 50.1 &. \\
$360 \mathrm{~Hz}$ and & Eddy.(W) & 628.7 & 375.1 & 200.6 &. \\
$\left.f_{\text {outer }} 180 \mathrm{~Hz}\right)$ & Excess(W) & 0.097 & 0.084 & 0.041 &. \\
& Total $(\mathrm{W})$ & 983.4 & 602.9 & 250.8 & 1837.1 \\
\hline
\end{tabular}
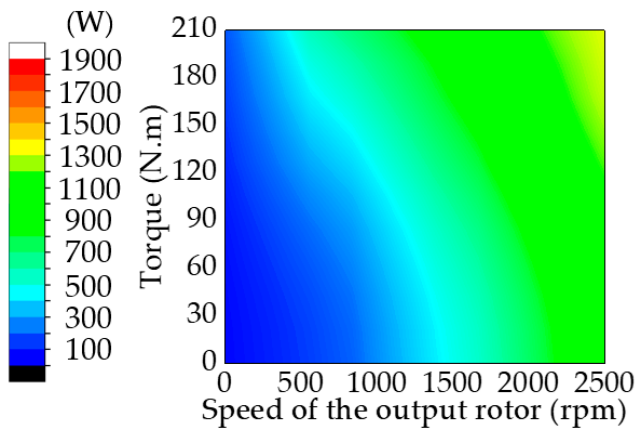

(a)
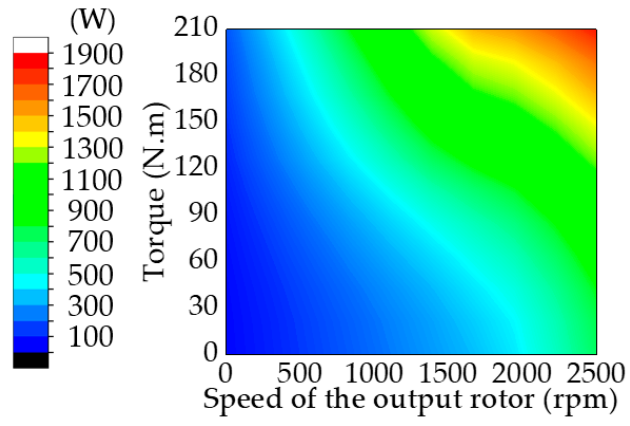

(c)

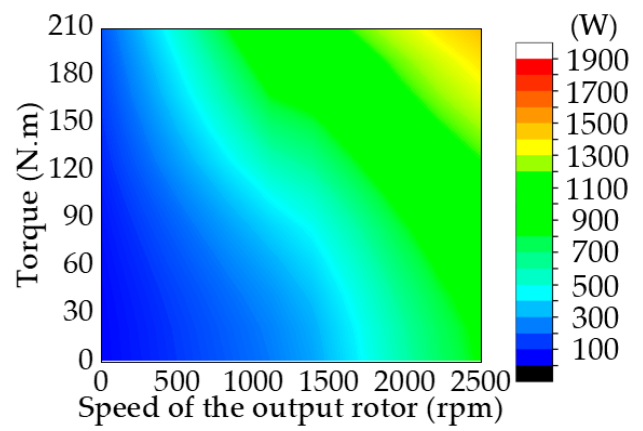

(b)

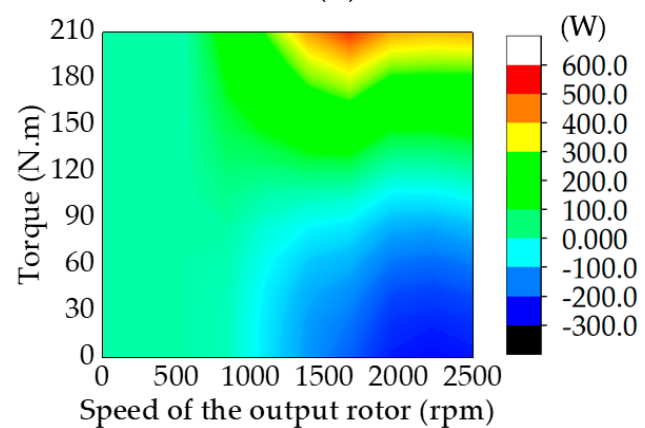

(d)

Figure 7. Iron loss map in the constant torque region according to the winding frequency when the amplitude of the inner winding current is adjusted and the outer winding current is fixed at the rated current (168 Arms). (a) Type I ( $f_{\text {inner }} 180 \mathrm{~Hz}$ and $\left.f_{\text {outer }} 360 \mathrm{~Hz}\right)$; (b) Type II $\left(f_{\text {inner }} 270 \mathrm{~Hz}\right.$ and $f_{\text {outer }} 270 \mathrm{~Hz}$ ); (c) Type III ( $f_{\text {inner }} 360 \mathrm{~Hz}$ and $f_{\text {outer }} 180 \mathrm{~Hz}$ ); (d) Difference between Type III and Type I. 


\section{Efficiency Improvement Strategy}

As presented in Section 3, in the DFMGM, the iron loss characteristics are varied with the frequencies of the inner and outer windings. Thus, the efficiency, which depends on the iron loss, is also changed, and the DFMGM is operated with the frequency combinations which obtains the maximum efficiency. Furthermore, at the multiple operating points, if the DFMGM is operated with the frequency combinations with the maximum efficiency, the overall operating efficiency is improved as compared with that of the case with only one frequency control sequence. Figure 8 a shows the minimum iron losses at each operating point using all frequency control sequences of Types I, II, and III, which means that the DFMGM is operated with reduced iron losses using the frequency combination selection according to the operating point. In addition to the iron loss, the copper loss map is shown in Figure $8 \mathrm{~b}$, and the maximum efficiency map is presented by the minimum iron loss map, copper loss map, and the output as shown in Figure 8c. In the high-speed and high-torque region, the maximum efficiency is $93.1 \%$, which shows that the efficiency increased as compared with $93.0 \%$ and $92.7 \%$ of the maximum efficiencies in Type II and Type III, respectively. To see the efficiency improvement over the whole operating region, the difference of the efficiency maps between Type III and Type I is presented in Figure 8d. In high-speed and low-torque region, maximally, there is a difference of 3.5\%, and Type III has higher efficiency as compared with those of Type I. In contrast, in the high-speed and high-torque region, the efficiencies of Type I are higher than those of Type III, and, maximally, there is a efficiency difference of $1.2 \%$. To sum up, these tendencies imply that efficiency improvement can be obtained by solely changing the frequency of the inner and outer windings, which are inherent characteristics of the DFMGM and a distinct difference from the general synchronous machine.

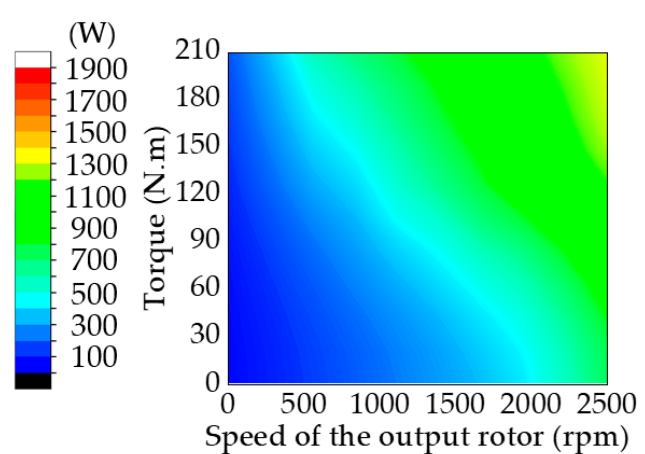

(a)

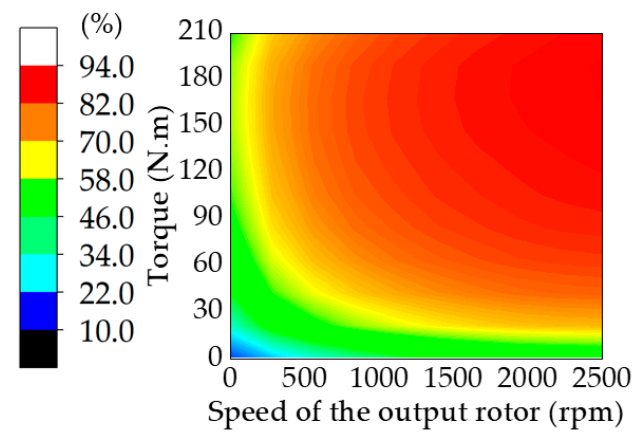

(c)

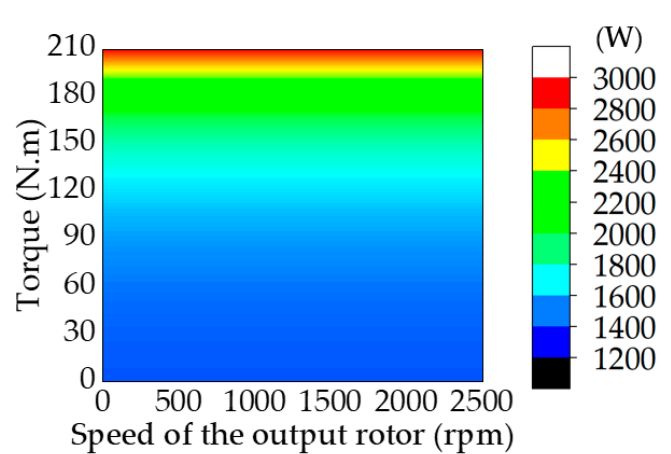

(b)

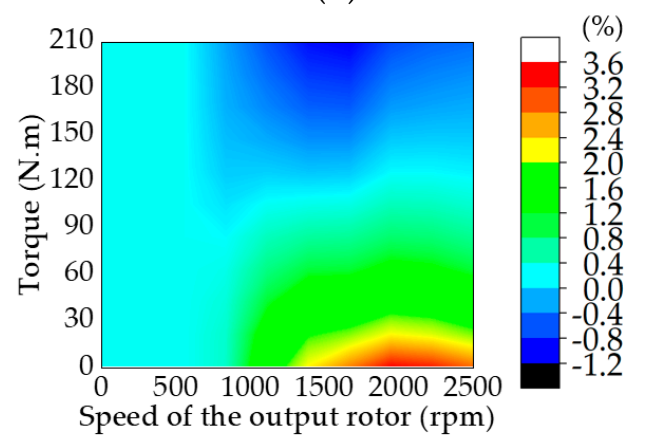

(d)

Figure 8. Loss and efficiency maps in the constant torque region according to the winding frequency when the amplitude of the inner winding current is adjusted and the outer winding current is fixed at the rated current (168 Arms). (a) Minimum iron loss map; (b) Copper loss map; (c) Maximum efficiency map; (d) Efficiency difference between Type III and Type I. 


\section{Role Exchange Analysis of Inner and Outer Windings}

The tendencies of the iron loss and efficiency presented in Sections 3 and 4 can be changed according to the frequency control sequence and the roles as the armature and field parts defined in Section 2. Namely, in this section, the roles of the inner and outer windings as the armature and field parts are switched with each other, that is, the inner winding (field part) current is fixed at the rated value and the outer winding (armature part) current is adjusted. Furthermore, with respect to the frequency control sequence, first, the outer winding frequency is increased, and then the inner winding frequency is changed. Hence, the inner and outer rated frequencies $\left(f_{\text {inner }}\right.$ and $\left.f_{\text {outer }}\right)$ are defined as $360 \mathrm{~Hz}$ and $180 \mathrm{~Hz}$ (Type I), $270 \mathrm{~Hz}$ and $270 \mathrm{~Hz}$ (Type II), and $180 \mathrm{~Hz}$ and $360 \mathrm{~Hz}$ (Type III), respectively, which are reversed as compared with the inner-armature case defined in Section 2.

Figures 9 and 10 show the characteristic map of the iron loss and efficiency, and these are derived using the same method as shown in Figures 7 and 8 in described in Sections 3 and 4. As shown in Figure $9 \mathrm{~d}$, in the high-speed region, Type III with low frequency at the inner winding has smaller iron losses than those of Type I with high frequency at the inner winding. Hence, as shown in Figure 10d, in the high-speed region, the efficiencies of the Type III are higher than those of type I, and especially, in the high-speed and low-torque region, maximally, the Type III has $7.7 \%$ higher efficiency than that of Type I. The maximum efficiency map over the whole operating region is drawn by all efficiency maps of Types I, II, and III in Figure 10c, and the maximum efficiency is $92.5 \%$ in the high-speed and high-torque region. This value is $0.6 \%$ lower than $93.1 \%$ of the inner-armature cases presented in Section 4.
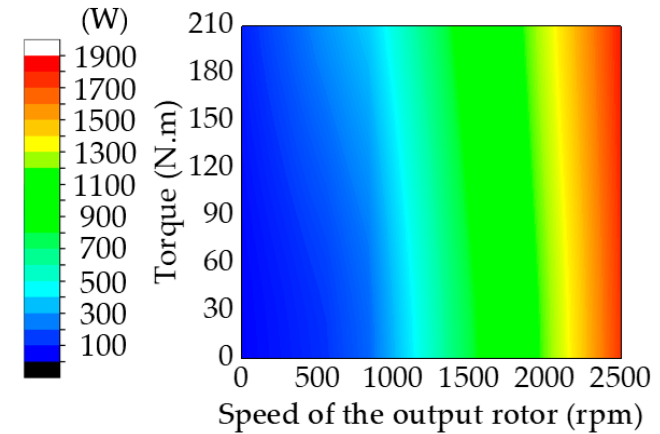

(a)

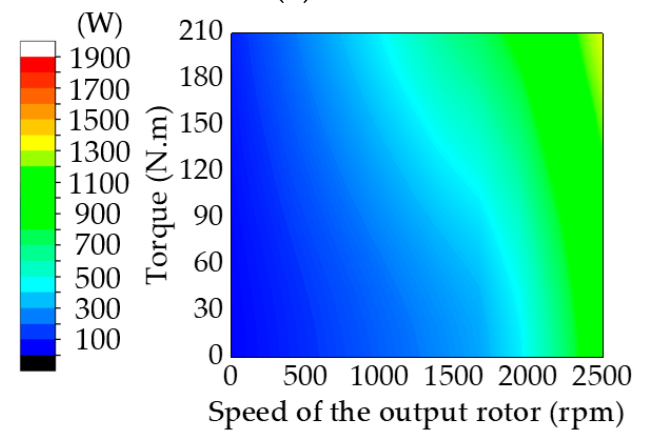

(c)

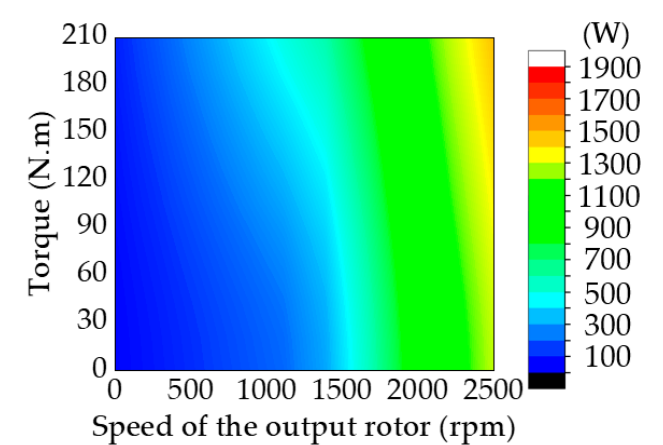

(b)

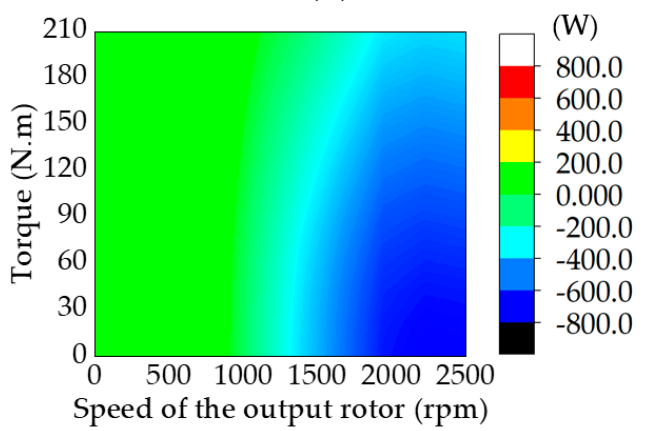

(d)

Figure 9. Iron loss map in the constant torque region according to the winding frequency when the amplitude of the outer winding current is adjusted and the inner winding current is fixed at the rated current (424 Arms). (a) Type I ( $f_{\text {inner }} 360 \mathrm{~Hz}$ and $f_{\text {outer }} 180 \mathrm{~Hz}$ ); (b) Type II ( $f_{\text {inner }} 270 \mathrm{~Hz}$ and $f_{\text {outer }} 270 \mathrm{~Hz}$ ); (c) Type III ( $f_{\text {inner }} 180 \mathrm{~Hz}$ and $f_{\text {outer }} 360 \mathrm{~Hz}$ ); (d) Difference between Type III and Type I.

Lastly, to compare the characteristics of the inner-armature case and the outer-armature case in detail, the iron loss map of the difference between the minimum iron loss maps of each case is presented in Figure 11a, and the efficiency map of the difference between the maximum efficiency maps of each case is drawn in Figure 11b. In the case of iron losses, the inner-armature case has higher 
values than those of the outer-armature case in the high-torque region. However, the efficiencies of the inner-armature case in most of the operating regions, except the high-torque region which is over $200 \mathrm{Nm}$, are higher than those of the outer-armature case. This is because the copper losses of the inner-armature case, shown in Figure 8b, are lower than those of the outer-armature case, shown in Figure 10b. Particularly, the inner-armature case has 5.7\% higher maximum efficiency than the outer-armature case in the low-speed region.

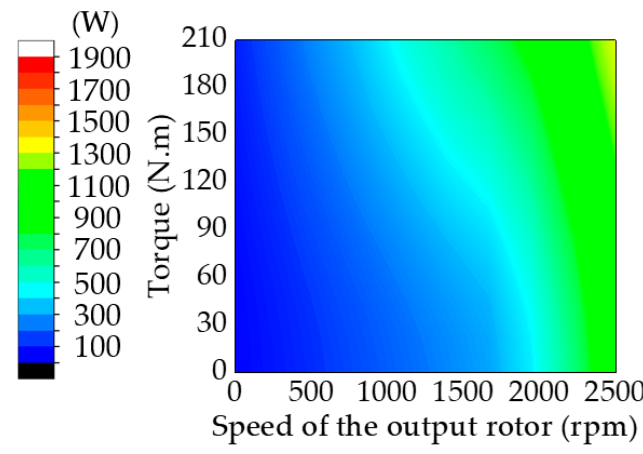

(a)

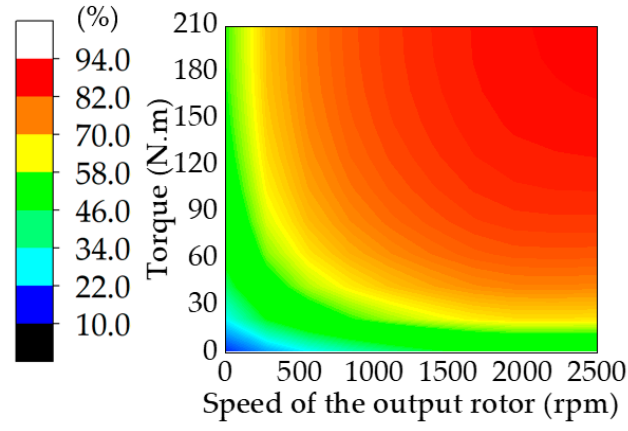

(c)

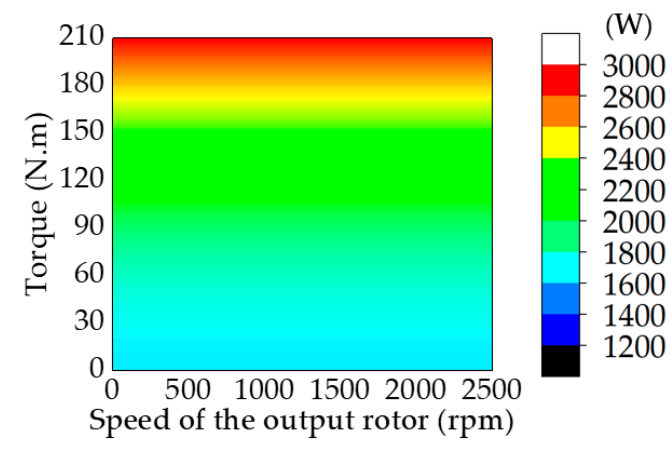

(b)

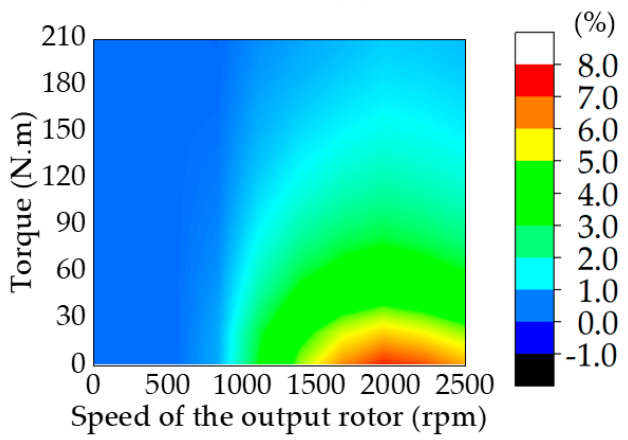

(d)

Figure 10. Loss and efficiency maps in the constant torque region according to the winding frequency when the amplitude of the inner winding current is adjusted and the outer winding current is fixed at the rated current (168 Arms). (a) Minimum iron loss map; (b) Copper loss map; (c) Maximum efficiency map; (d) Efficiency difference between Type III and Type I.

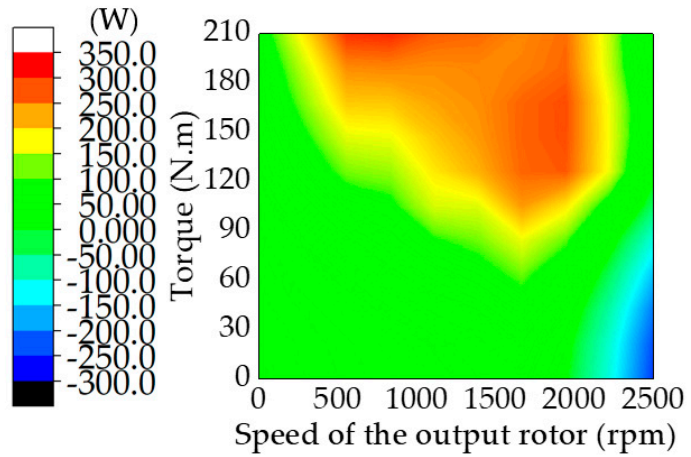

(a)

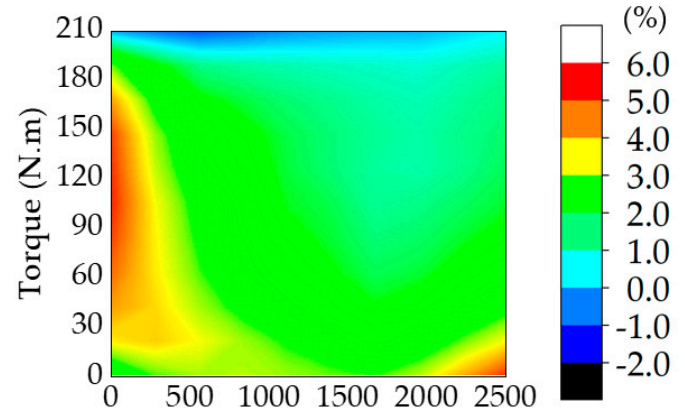

Speed of the output rotor (rpm)

(b)

Figure 11. Loss and efficiency maps. (a) Iron loss difference between minimum iron loss maps of the inner-armature case and outer-armature case; (b) Efficiency difference between maximum efficiency maps of the inner-armature case and outer-armature case. 


\section{Conclusions}

The operating principle and the division of the operating region are presented based on the individual frequency control in the inner and outer windings. In addition, the iron loss and efficiency characteristics are compared for three cases of different winding frequency conditions where the frequency control sequence of the inner and outer windings are defined and the inner and outer windings are operated as the armature and field parts, respectively. On the basis of the iron loss analysis, the results show that increasing the inner winding frequency can produce considerable iron loss due to magnetic saturation and the effect of inner winding flux on the outer stator. Furthermore, in the efficiency analysis, the maximum efficiency maps over the constant torque region are obtained using all winding frequency combinations, and it shows that, maximally, there is a difference of $3.5 \%$ in the efficiency with the different control strategies and a maximum efficiency of $93.1 \%$ is obtained. In addition to this inner-armature case, the frequency control sequence and the roles of the inner and outer windings as the armature and field parts are changed, and the analysis of the iron loss and efficiency are repeated. In the outer-armature case, the results show that, maximally, there is a difference of $7.7 \%$ efficiency between different strategies and a maximum efficiency of $92.5 \%$ is obtained. Namely, by selecting this frequency combination and the individual frequency control with respect to the inner and outer windings, the possibility of improving the overall operating efficiency over the multiple operating points is presented. Moreover, the performances of a DFMGM could be significantly improved if this study regarding individual frequency design and efficiency improvement by selection of the frequency combinations was expanded to comprehensive research that considered a greater number of frequency combinations, the whole operating region including the field-weakening region, and an optimization process for the frequency combination.

Author Contributions: H.S. developed the basic concept of the efficiency improvement strategy and implemented the validation of the concept, formal analysis, investigation, and original draft preparation. J.C. took charge of review, editing, supervision, and project administration. All authors have read and agreed to the published version of the manuscript.

Funding: This research was funded by the Basic Science Research Program through the National Research Foundation of Korea (NRF) funded by the Ministry of Education, grant number NRF-2018R1D1A1B07050279.

Conflicts of Interest: The authors declare no conflict of interest.

\section{References}

1. Atallah, K.; Calverely, S.D.; Howe, D. Design, analysis and realization of a high-performance magnetic gear. IEE Proc.-Electr. Power Appl. 2004, 151, 135-143. [CrossRef]

2. Fan, Y.; Gu, L.; Luo, Y.; Han, X.; Cheng, M. Investigation of a new flux-modulated permanent magnet brushless motor for EVs. Sci. World J. 2014, 2014, 540797. [CrossRef] [PubMed]

3. Wang, L.L.; Shen, J.X.; Luk, P.C.K.; Fei, W.Z.; Wang, C.F.; Hao, H. Development of a magnetic-geared permanent-magnet brushless motor. IEEE Trans. Magn. 2009, 45, 4578-4581. [CrossRef]

4. Jian, L.; Gong, W.; Xu, G.; Liang, J.; Zhao, W. Integrated magnetic-geared machine with sandwiched armature stator for low-speed large-torque applications. IEEE Trans. Magn. 2012, 48, 4184-4187. [CrossRef]

5. Zhang, X.; Liu, X.; Chen, Z. A novel coaxial magnetic gear its integration with permanent-magnet brushless motor. IEEE Trans. Magn. 2016, 52, 1-4. [CrossRef]

6. Fan, Y.; Zhang, L.; Huang, J.; Han, X. Design, analysis, and sensorless control of a self-decelerating permanent-magnet in-wheel motor. IEEE Trans. Ind. Electron. 2014, 61, 5788-5797.

7. Liu, C.; Lee, C.H.T.; Chen, M. Comparison of outer-rotor permanent magnet machines for in-wheel drives. In Proceedings of the 2013 IEEE International Symposium on Industrial Electronics, Taipei, Taiwan, 28-31 May 2013. [CrossRef]

8. Rasmussen, P.O.; Frandsen, T.V.; Jensen, K.K.; Jessen, K. Experimental evaluation of a motor-integrated permanent-magnet gear. IEEE Trans. Ind. Appl. 2013, 49, 850-859. [CrossRef]

9. Frandsen, T.V.; Mathe, L.; Berg, N.I.; Holm, R.K.; Matzen, T.N.; Rasmussen, P.O.; Jensen, K.K. Motor integrated permanent magnet gear in a battery electrical vehicle. IEEE Trans. Ind. Appl. 2013, 51, 1516-1525. [CrossRef] 
10. Guo, X.; Wu, S.; Fu, W.; Liu, Y.; Wang, Y.; Zeng, P. Control of a dual-stator flux-modulated motor for electric vehicles. Energies 2016, 9, 517. [CrossRef]

11. Chen, Y.; Fu, W.; Weng, X. A concept of general flux-modulated electric machines based on a unified theory and its application to developing a novel doubly-fed dual-stator motor. IEEE Trans. Ind. Electron. 2017, 64, 9914-9923. [CrossRef]

12. Shin, H.; Chang, J. Characteristics analysis of doubly fed magnetic geared motor considering winding frequency conditions. Energies 2018, 11, 2564. [CrossRef]

13. Wang, Y.; Ho, S.L.; Fu, W.N.; Shen, J.X. A novel brushless doubly fed generator for wind power generation. IEEE Trans. Magn. 2012, 48, 4172-4175. [CrossRef]

14. Khaliq, S.; Atiq, S.; Lipo, T.A.; Kwon, B.I. Rotor pole optimization of novel axial-flux brushless doubly fed reluctance machine for torque enhancement. IEEE Trans. Magn. 2016, 52, 1-4. [CrossRef]

15. Jiang, Y.; Zhang, J.; Li, T. A segmented brushless doubly fed generator for wind power applications. IEEE Trans. Magn. 2018, 54, 1-4. [CrossRef]

16. Shin, H.M.; Chang, J.H. Comparison of radial force at modulating pieces in coaxial magnetic gear and magnetic geared machine. IEEE Trans. Magn. 2018, 54,1-4. [CrossRef]

17. Fiorillo, F.; Novikov, A. An improved approach to power losses in magnetic laminations under nonsinusoidal induction waveform. IEEE Trans. Magn. 1990, 26, 2904-2910. [CrossRef]

18. Lee, J.H. Efficiency evaluations of synchronous reluctance motor using coupled FEM and Preisach modeling. IEEE Trans. Magn. 2003, 39, 3271-3273. [CrossRef]

19. Jian, L.; Chau, K.T.; Gong, Y.; Jiang, J.Z.; Yu, C.; Li, W. Comparison of coaxial magnetic gears with different topologies. IEEE Trans. Magn. 2009, 45, 4526-4529. [CrossRef]

(C) 2020 by the authors. Licensee MDPI, Basel, Switzerland. This article is an open access article distributed under the terms and conditions of the Creative Commons Attribution (CC BY) license (http://creativecommons.org/licenses/by/4.0/). 